\title{
Prognostic significance of right ventricular ejection fraction for persistent complex ventricular arrhythmias and/or sudden cardiac death after first myocardial infarction: Relation to infarct location, size and left ventricular function
}

\author{
M. Pfisterer, H. Emmenegger, M. Solèr and F. Burkart \\ Division of Cardiology, Department of Internal Medicine and Division of Nuclear Medicine, \\ Institute of Radiology, University Hospital, Basel, Switzerland
}

\begin{abstract}
KEY WORDS: Right ventricular ejection fraction, complex ventricular arrhythmias, sudden cardiac death, prognosis, myocardial infarction, left ventricular ejection fraction.

To assess the prognostic significance of right ventricular dysfunction after a first myocardial infarction for complex ventricular arrhythmias and or sudden cardiac death in relation to infarct location, size and left ventricular function, a series of 127 consecutive patients was prospectively studied and followed up for one year. Prior to hospital discharge, a 24-hour electrocardiographic recording and radionuclide angiocardiography were performed. Right ventricular ejection fraction was related to inferior infarct location and size $(r=0.45, \mathrm{P}<0.01)$ : similarly left ventricular ejection fraction was related to anterior infarct location and size $(r=0 \cdot 76, \mathrm{P}<0 \cdot 001)$. The incidence of severe ventricular arrhythmias was significantly higher in patients with isolated right or left ventricular dysfunction compared to patients with normal function; it was highest in patients with severe depression of both ventricles. Patients with complex ventricular arrhythmia and/or sudden cardiac death had significantly reduced left and right ventricular ejection fractions. Detailed analysis in patients with left ventricular ejection fraction $>0.40 \mathrm{vs}$. $\leqslant 0.40$ showed that presence of complex ventricular ectopic activity and/or sudden cardiac death after myocardial infarction was related not only to left, but also independently to right ventricular dysfunction. These results imply a significant prognostic contribution of right ventricular dysfunction to the occurrence of severe ventricular arrhythmias and/or sudden cardiac death after myocardial infarction independent of and additive to left ventricular dysfunction.
\end{abstract}

In addition to a history of previous myocardial infarction, left ventricular dysfunction ${ }^{[1-7]}$ and persistent complex ventricular arrhythmias ${ }^{[7-12]}$ have been identified as the most important predictors of prognosis after myocardial infarction. Obviously, there is some interrelation between these variables ${ }^{[17,11,13]}$ but a number of reports have pointed to the independent contribution of ventricular ectopic activity to prognosis ${ }^{[8-12]}$. In previous studies, we and others have noted that myocardial

Submitted for publication on 12 August 1985 and in revised form 28 October 1985

This study was supported by grant $3.966-0.80$ from the Swiss National Foundation for Scientific Research, Berne, Switzerland.

Address for reprints: M. Pfisterer, M.D., Division of Cardiology, Department of Internal Medicine, University Hospital, CH-4031 Basel/Switzerland. infarction not only affects left but also right ventricular function, especially in patients with inferior $Q$ waves ${ }^{[14-19]}$. Other studies of patients with chronic coronary artery disease have identified a small sub-group of patients with disease confined to the right coronary artery in whom only right ventricular ejection fraction (EF) was abnormal during exercise-induced ischemia ${ }^{[20-22]}$. Since right ventricular dysfunction may also be related to complex ventricular arrhythmias such as occurs in patients with pulmonary embolism ${ }^{[23]}$ or chronic obstructive pulmonary disease ${ }^{[24]}$, it could provide an explanation for the incomplete association between complex ventricular arrhythmias and depressed left ventricular function after myocardial infarction. We therefore started a prospective study to assess the prognostic significance of right ventricular dysfunction after a first 
myocardial infarction for occurrence of complex ventricular arrhythmias and sudden death and to relate these findings to clinical signs, symptoms, infarct location, and left ventricular function.

\section{Methods}

PATIENTS

Between July 1981 and November 1982, all patients below 70 years of age admitted to the coronary care unit of the University Hospital of Basel with the diagnosis of a first definite or impending myocardial infarction were considered for inclusion in this study. Criteria for diagnosis included a typical history of chest pain within 24 hours of admission to the coronary care unit, serial changes on the ECG and abnormalities in serial creatine kinase determinations (at least 2 of 3 criteria for definite infarction according to WHO recommendations ${ }^{[25]}$. Patients with life-threatening accompanying disease, requiring urgent cardiac surgery or dying during the initial hospitalisation as well as those living too far away for later followup were excluded from the study (Table 1). In addition, 3 patients had to be excluded because the radionuclide study could not be analysed properly for technical reasons or because of atrial fibrillation. There were no deaths during follow-up in these 3 patients.

The remaining 147 patients who met the selection criteria and survived the acute event were studied: 119 men and 28 women with an age range between 28 and 70 years, mean 59 years. The diagnosis of a myocardial infarction could be firmly

Table I Patient selection or exclusion

\begin{tabular}{lc}
\hline Total number of patients admitted & \\
$\quad$ to CCU Jul 1981-Nov 1981 & 465 \\
Age > 70 years & 177 \\
Previous myocardial infarction & 73 \\
Total patients with first infarction & \\
$\quad$ <age 70 & $215(100 \%)$ \\
& \\
Excluded for: & $19(9 \%)$ \\
$\quad$ accompanying severe disease & $8(4 \%)$ \\
emergency cardiac surgery & $17(8 \%)$ \\
death during initial hospitalisation & $21(10 \%)$ \\
living far away/no follow-up possible & $3(1 \%)$ \\
technical reasons & $147(68 \%)$ \\
Final study population & 127 \\
$\quad$ with definite infarction & 20 \\
unstable angina &
\end{tabular}

$\mathrm{CCU}-$ coronary care unit established in 127; these formed the study population. The appearance of Q-waves of at least $0.04 \mathrm{~s}$ duration were considered diagnostic for transmural (Q-wave) infarction and isolated ST- and $T$-wave changes for non-transmural (non-Q-wave) infarction. Twenty-eight patients had an anterior Q-wave infarction (including antero-septal and antero-lateral; main ECG changes in leads I, aVL and/or $\mathrm{V}_{1-5}$ ), 64 an inferior Q-wave infarction (changes in leads II, III, aVF, including 39 patients with additional anterior ST-segment depression: 'infero-posterior' $\left[\mathrm{V}_{1}-\mathrm{V}_{3}\right]$ and 'inferolateral' $\left[V_{4}-V_{6}\right]$ ), and 35 patients a non-Q-wave infarction. In 20 additional patients, the typical history of prolonged ( $>15 \mathrm{~min}$ ) ischaemic chest pain at rest was not followed by ECG or enzyme changes and the diagnosis of unstable angina was made; these patients were followed separately.

\section{STUDY PROTOCOL AND FOLLOW-UP}

The day before hospital discharge $(14 \cdot 1 \pm 5 \cdot 7$ days after admission) and after discontinuation of all antiarrhythmic and if possible antianginal therapy for at least 24 hours, a 24 hour ambulatory ECG recording was made during routine hospital activities. In addition, all patients had ECG gated equilibrium radionuclide ventriculography at rest for determination of left and right ventricular EF and wall motion. The clinical status of all patients as determined by physical examination, resting ECG and chest X-ray was prospectively evaluated prior to hospital discharge and then reevaluated at 3, 6 and 12 months after hospital admission. In addition, each patient was followed by his or her private physician who had access to all study results and who regulated therapy.

This study protocol was approved by this institution's Ethical Committee in January 1981 and by the Swiss National Foundation for Scientific Research in March 1981. At hospital discharge, patients were given the following drugs: betaadrenoceptor blocking-drugs (47 patients), calcium antagonists (65), long acting nitrates (25), antiarrhythmic agents (24), anticoagulants (118), digitalis (26) and diuretic or vasodilator drugs (25). Twenty-nine patients had no therapy at all and 16 only anticoagulants. Follow-up was complete in all 147 patients.

24-HOUR ELECTROCARDIOGRAPHIC RECORDINGS AND ANALYSIS

24 hour recordings were made on a Dynagram model 5000 cassette recorder and played back at 60 
times real-time speed on an ICR (Instruments for Cardiac Research Inc., Syracuse, New York/USA) model $6004 \mathrm{C}$ Holter electrocardioscanner and the entire 24-hour electrocardiogram plotted, condensed beat-by-beat on fibreoptic paper. Arrhythmias detected by trained personnel were written out at normal paper speed and analysed by a cardiologist according to Lown's classification ${ }^{[26]}$ and the number of ventricular premature beats per hour. Complex ventricular arrhythmias were considered present if Lown's classes IV A and B (or V) ectopics were registered during two separate one hour periods (grade $\mathrm{V}$ arrhythmias did not occur separately and were disregarded); Lown's class III ectopic activity was analysed separately and considered as potentially severe arrhythmias. The electrocardiographic tapes were read independently of clinical presentation, radionuclide ventriculographic results or subsequent course.

\section{RADIONUCLIDE ANGIOCARDIOGRAPHY}

Gated equilibrium radionuclide data were accumulated after in vivo red cell labelling with $25 \mathrm{mCi}$ technetium- $99 \mathrm{~m}$. Imaging was accomplished in a modified left anterior oblique projection with a conventional scintillation camera equipped with a high-sensitivity collimator. Global left and right ventricular $\mathrm{EF}$ values were determined according to previously validated techniques ${ }^{[19,27,28]}$. In short, global left ventricular EF was computed. from composite time-activity curves using a special computer algorhythm (MUGE/Medtronic/MDS $\mathrm{A}^{2}$ system). For right ventricular EF determination, smoothed and background subtracted end-diastolic and end-systolic images were outlined separately using the well-defined end-systolic atrio-ventricular borders as a fixed marker. These techniques have been shown to be highly reproducible in our laboratory with low inter- and intra- observer variabilities (left ventricular $\mathrm{EF} \pm 2 \cdot 5$ $\mathrm{EF} \%$ and $\pm 2 \cdot 2 \mathrm{EF} \%$, right ventricular $\mathrm{EF} \pm 3 \cdot 8$ EF\% and $\pm 3.6 \mathrm{EF} \%$, respectively). The lower limit for a normal left ventricular EF has been defined as 0.50 , and for right ventricular $E F$ as $0 \cdot 40^{[19,29]}$. For the present study, a significantly depressed left ventricular EF was defined as $<0.40$ and a significantly depressed right ventricular EF as $<0.35$. Regional left ventricular EF was calculated routinely by an automated computer method previously validated and described ${ }^{[30,31]}$. In order to assess the contribution of septal motion to right ventricular dysfunction, the antero-septal and apical regional EF were analyzed and contraction of the septum scored visually. All radionuclide ventriculographic data were analysed independently and without knowledge of clinical or other results.

\section{STATISTICAL ANALYSIS}

Data are presented as mean \pm 1 standard deviation or frequencies. Two-sample comparisons were performed by means of the t-test for unpaired samples and multiple comparisons by means of the Tukey-Kramer approach. Differences between proportions were assessed using a chi-square analysis and partitioning of the chi-square was done according to Brandt-Snedecor.

\section{Results \\ COMPLEX VENTRICULAR ARRHYTHMIAS}

The incidence of significant ventricular ectopic activity at hospital discharge in relation to infarct location is summarised in Table 2. Twenty-four percent of patients with a Q-wave infarction showed Lown's class IV arrhythmias versus only $5 \%$ of patients with unstable angina $(P<0.05)$. There were no significant differences between

Table 2 Incidence of ventricular ectopic activity in relation to infarct location. There were no significant differences between patients with anterior, inferior or non- $Q$-wave infarctions

\begin{tabular}{lcccc}
\hline & $\begin{array}{c}\text { Anterior } \\
\text { MI } \\
(N=28)\end{array}$ & $\begin{array}{c}\text { Inferior } \\
\text { MI } \\
(N=64)\end{array}$ & $\begin{array}{c}\text { Non Q-wave } \\
\text { MI } \\
(N=35)\end{array}$ & $\begin{array}{c}\text { Unstable } \\
\text { angina } \\
(N=20)\end{array}$ \\
\hline Lown IV & $4(14 \%)$ & $18(28 \%)$ & $4(11 \%)$ & $1(5 \%)$ \\
Lown III & $5(18 \%)$ & $3(5 \%)$ & $4(11 \%)$ & $1(5 \%)$ \\
Lown 0-II & $19(68 \%)$ & $43(67 \%)$ & $27(77 \%)$ & $18(90 \%)$ \\
\hline
\end{tabular}

MI-myocardial infarction 
Table 3 Left and right ventricular ejection fraction in relation to infarct location. Depressed LVEF in patients with anterior infarction and depressed RVEF in patients with inferior infarction $(P<0.001)$.

\begin{tabular}{lcccc}
\hline & $\begin{array}{c}\text { Anterior } \\
\text { MI } \\
(N=28)\end{array}$ & $\begin{array}{c}\text { Inferior } \\
M I \\
(N=64)\end{array}$ & $\begin{array}{c}\text { Non Q-wave } \\
\text { MI } \\
(N=35)\end{array}$ & $\begin{array}{c}\text { Unstable } \\
\text { angina } \\
(N=20)\end{array}$ \\
\hline LVEF $(\%)$ & $\begin{array}{c}38 \cdot 0 \pm 15 \cdot 6 \\
\text { Frequency } \leqslant 40 \%\end{array}$ & $\begin{array}{c}52 \cdot 2 \pm 14(50 \%) \\
12(19 \%)\end{array}$ & $\begin{array}{c}58 \cdot 3 \pm 9 \cdot 6 \\
2(6 \%)\end{array}$ & $\begin{array}{c}62 \cdot 9 \pm 8 \cdot 5 \\
0(0 \%)\end{array}$ \\
RVEF $(\%)$ & $\begin{array}{c}0 \cdot 9 \pm 9 \cdot 5 \\
\text { Frequency } \leqslant 35 \%\end{array}$ & $\begin{array}{c}31 \cdot 5 \pm 9 \cdot 3 \\
4(18 \%)\end{array}$ & $\begin{array}{c}44(69 \%) \\
6(17 \%)\end{array}$ & $\begin{array}{c}45 \cdot 1 \pm 6 \cdot 0 \\
0(0 \%)\end{array}$ \\
\hline
\end{tabular}

LVEF-Left ventricular ejection fraction, MI-myocardial infarction, RVEF-right ventricular ejection fraction.

patients with $\mathrm{Q}$-wave and non-Q-wave infarction, and roughly $70 \%$ of them had no or only insignificant arrhythmias versus $90 \%$ of patients with unstable angina.

RIGHT AND LEFT VENTRICULAR DYSFUNCTION IN RELATION TO INFARCT LOCATION AND SIZE

Right and left ventricular EF data are shown in relation to infarct location in Table 3. The function of both ventricles was normal in patients without infarction and slightly depressed in a minority of patients with non-Q-wave infarctions, but the mean values of the latter group still lay within normal limits. In contrast, a majority of patients with Q-wave inferior infarctions had a severely depressed right ventricular EF resulting in a mean value of $31 \cdot 5 \pm 9 \cdot 3 \%$, whereas left ventricular EF in this group of patients remained at the lower limit of normal $(52 \cdot 2 \pm 13 \cdot 2 \%)$. An opposite pattern of left and right ventricular function was noted in patients with $\mathrm{Q}$-wave anterior infarction: severely depressed left ventricular EF (average $38 \cdot 0 \pm 15 \cdot 6 \%$ ) but still normal right ventricular EF (mean $40.9 \pm 9.5 \%$ ). Left ventricular EF was significantly different between patients with inferior vs. anterior infarction and so was right ventricular EF (both $P<0.0001$ ). The percentage of patients with severely depressed left ventricular EF in the group with anterior infarction was similar to that of patients with severely depressed right ventricular $\mathrm{EF}$ in the group with inferior infarction and vice versa (Table 3 ).

For all patients with myocardial infarction, there was no overall correlation between right and left ventricular EF $(r=0 \cdot 28)$, although patients with a left ventricular EF $<0.40$ had a lower mean right ventricular EF than patients with a normal left ventricular EF of $>0.50(33.6 \pm 8.5 \% v s$.
$38 \cdot 2 \pm 9.4 \%, P<0.05)$. The subgroup of patients with inferior infarction combined with anterior ST-segment depression (infero-posterior or inferolateral infarction) had significantly lower left ventricular EF than patients with infarction limited to inferior electrocardiographic leads $(48 \cdot 6 \pm 14 \cdot 3 \%$ vs. $57 \cdot 0 \pm 10.7 \%, \quad P<0.01)$. The electrocardiographic site of infarction in the 16 patients with severely depressed bi-ventricular function was anterior in 5 and inferior in 11 cases, all of whom had additional anterior ST-depression. None of these patients had clinical or electrocardiographic evidence of previous infarction. Twenty-five patients with electrocardiographic signs of posterior wall involvement ( $R$-wave increase in leads $V_{1}$ and/or $V_{2}$ ) had a somewhat lower right ventricular EF than the remaining patients with inferior Q-wave infarction, although this difference was not statistically significant $(29 \cdot 9 \pm 7.0$ vs. $32 \cdot 2 \pm 9 \cdot 9 \%$ ).

Analysis of regional right ventricular function showed a significant relation between wall motion score of the right ventricular free wall and apex and right ventricular EF: right ventricular EF was $42.5 \pm 6.9 \%$ in 91 patients with apparently normal right ventricular contraction, $31 \cdot 1 \pm 7.4 \%$ in 44 patients with hypokinetic and $20 \cdot 2 \pm 4.6 \%$ in 12 patients with virtually akinetic right ventricular free wall and apex $(P<0.001$ between groups). No relation was found, however, between abnormal septal motion of the left ventricular cavity or anteroseptal regional EF and global right ventricular function.

\section{FOLLOW-UP/MORTALITY}

During the follow-up of 12 months, 8 patients died, 7 of them suddenly. The first year mortality 
Table 4 One-year mortality: $8 / 127(6.3 \%)$ in relation to left and right ventricular ejection fraction and ventricular ectopic activity

\begin{tabular}{|c|c|c|c|c|c|c|c|c|}
\hline $\begin{array}{l}\text { Age } \\
\text { (years) }\end{array}$ & Sex & $\begin{array}{c}\text { Infarct } \\
\text { site (ECG) }\end{array}$ & & LVEF & RVEF & $\begin{array}{c}\text { VEA } \\
\text { Lown } />10 h^{-1}\end{array}$ & Death & $\begin{array}{l}\text { Days after } \\
\text { infarct }\end{array}$ \\
\hline 66 & $\mathbf{M}$ & inf post lat & $Q$ & 0.32 & 0.28 & $I V \mid-$ & sudden & 205 \\
\hline 68 & $\mathbf{F}$ & inf post lat & $Q$ & 0.19 & $0 \cdot 19$ & $I V I+$ & sudden & 63 \\
\hline 69 & $\mathbf{M}$ & ant sept & $\mathrm{Q}$ & $0 \cdot 22$ & 0.08 & $I V /+$ & sudden & 62 \\
\hline 60 & $\mathrm{~F}$ & ant sept & $\mathbf{Q}$ & $0 \cdot 3 I$ & 0.37 & $\mathrm{I} /-$ & sudden & 114 \\
\hline 64 & $\mathbf{M}$ & ant sept lat & $\mathbf{Q}$ & $0 \cdot 14$ & 0.50 & $I V /+$ & sudden & 26 \\
\hline 62 & $\mathbf{M}$ & inf post & $\mathrm{Q}$ & 0.45 & 0.20 & $\mathrm{III} /-$ & sudden & 33 \\
\hline 61 & $\mathbf{M}$ & inf lat & $\mathrm{Q}$ & 0.51 & $0 \cdot 26$ & $\mathrm{I} /-$ & sudden & 18 \\
\hline 68 & $\mathbf{M}$ & lat & $\mathrm{nQ}$ & 0.65 & 0.42 & $\mathrm{III} /+$ & $\begin{array}{l}\text { re-infarct, } \\
\text { shock }\end{array}$ & 169 \\
\hline
\end{tabular}

ant-anterior, inf-inferior, lat-lateral, LVEF-left ventricular ejection fraction, $\mathrm{nQ}$ non-Q-wave infarction, post-posterior, $\mathrm{Q}-\mathrm{Q}$-wave infarction, $\mathrm{RVEF}$-right ventricular EF, sept-septal, VEA-ventricular ectopic activity. Numbers in italics: severely abnormal values as defined for this study.

Table 5 Relation between left/right ventricular ejection fraction and ventricular ectopic activity (127 patients with myocardial infarction). Chi square significance for complex ventricular arrhythmias Lown IV $\mathrm{P}<0.001$; for significance between subgroups see text

\begin{tabular}{lcccc}
\hline & $\begin{array}{c}\text { LVEF }>0.40 \\
\text { RVEF }>0.35 \\
(N=60)\end{array}$ & $\begin{array}{c}>0.40 \\
(N=3.35\end{array}$ & $\begin{array}{c}\leqslant 0.40 \\
>0.35 \\
(N=12)\end{array}$ & $\begin{array}{c}\leqslant 0.40 \\
(N=16)\end{array}$ \\
\hline Lown IV & $4(7 \%)$ & $9(23 \%)$ & $3(25 \%)$ & $10(63 \%)$ \\
Lown III & $4(7 \%)$ & $4(10 \%)$ & $4(33 \%)$ & $0(0 \%)$ \\
Lown 0-II & $52(87 \%)$ & $26(67 \%)$ & $5(42 \%)$ & $6(37 \%)$ \\
\hline
\end{tabular}

LVEF-left ventricular ejection fraction, RVEF-right ventricular ejection fraction

rate in those patients having survived a first myocardial infarction was $6 \cdot 3 \%$. Table 4 relates these deaths to infarct location, biventricular function and ventricular ectopic activity. All patients who died suddenly (within 1 hour of onset of symptoms, all witnessed) had severe depression of either left $(2$ patients), or right (2 patients), or biventricular ( 3 patients) function at hospital discharge and 4 had Lown grade IV arrhythmia. All of these patients were in the age group between 60 and 69 years. Three of 4 patients with complex ventricular ectopic activity at hospital discharge were on antiarrhythmic therapy at the time of death; this therapy had been shown to reduce arrhythmias effectively on repeated ambulatory ECGs in all 3 patients. The one patient who died after reinfarction in pump failure had normal biventricular function after a non-Q-wave lateral infarction and Lown grade III arrhythmia at the end of his initial hospitalisation.
Clinical signs of right heart failure at the time of the radionuclide study were rare: only 5 patients who all had a depressed right ventricular EF (average $24.5 \pm 7.9 \%$ ) had a positive hepatojugular reflux and none had increased jugular venous pressure without provocation. During follow-up, 4 additional patients developed clinical signs of right heart failure; they had a mean right ventricular EF of $29 \cdot 3 \pm 9 \cdot 8 \%$ at hospital discharge. Overall, patients with a positive hepatojugular reflux at any time during the study had a significantly lower right ventricular EF than the remaining patients $(26.9 \pm 8 \cdot 7 \%$ vs. $38 \cdot 1 \pm 9 \cdot 7 \%$, $P<0.001)$.

RELATION BETWEEN COMPLEX ARRHYTHMIAS/SUDDEN CARDIAC DEATH AND BIVENTRICULAR FUNCTION

The relation between ventricular ectopic activity and left and/or right ventricular dysfunction in patients with definite infarction is shown in Table 


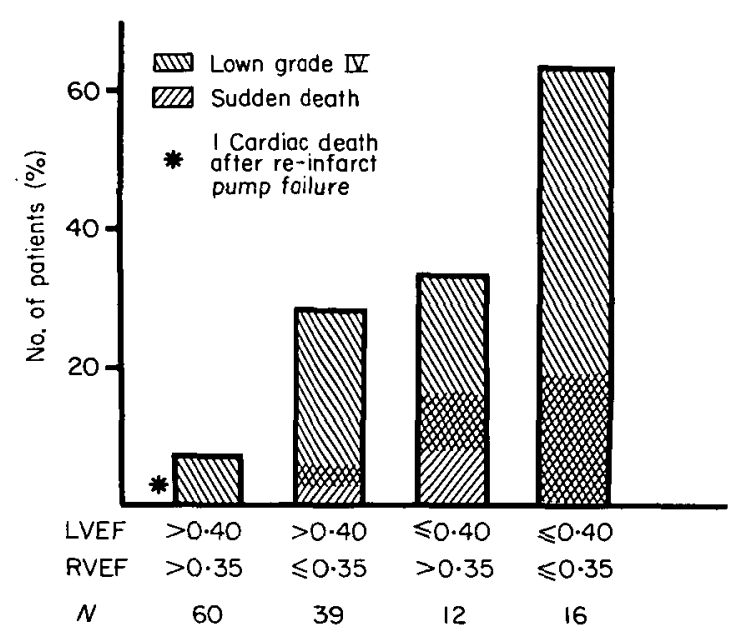

Figure 1 Relation between left/right ventricular EF and complex ventricular arrhythmias/sudden cardiac death. The group at left with almost normal biventricular function differed significantly $(P$ at least $<0.05)$ from each of the other three groups with regard to ventricular arrhythmias and sudden cardiac death, and the group with marked biventricular dysfunction differed significantly $(P<0.001)$ from each of the other three groups. (LVEF-left ventricular ejection fraction, RVEF_right ventricular ejection fraction).

5. Patients are grouped as follows: those with normal or only moderately depressed function (left ventricular EF $>0.40$ and right ventricular EF $>0.35$ ); those with either marked isolated depressed right (right ventricular EF $<0.35$ ) or left ventricular function (left ventricular EF $<0.40$ ); and those with severe biventricular dysfunction (EF of both ventricles $<0.40$ and $<0.35$ respectively). Patients with normal or only moderately depressed biventricular function had significantly fewer complex ventricular arrhythmias than those of any of the other three groups ( $P$ at least $<0.05$ ). Clearly the highest incidence was found in patients with severely depressed biventricular function ( $P<0.005$ vs other groups). On the other hand, there was a gradual decrease in the incidence of no or only insignificant ventricular arrhythmias from the group of patients with almost normal biventricular function to the group of patients with markedly depressed function of both ventricles.

Overall, patients with complex arrhythmias Lown's class IV and/or sudden cardiac death, had significantly depressed left $(0.43 \pm 0.15$ vs. $0.53 \pm 0.14 ; P<0.005)$ and right ventricular $\mathrm{EF}$ $(0.31 \pm 0.09$ vs. $0.38 \pm 0.09 ; P<0.001)$. The relationship between Lown's class IV arrhythmia, sudden cardiac death and biventricular function is shown in Fig. 1. Again, the incidence of complex arrhythmias and/or sudden cardiac death was significantly lower in the group of patients with almost normal function of both ventricles when compared to each of the other three groups $(P$ at least $<0.05$ ); the highest incidence was found in patients with marked biventricular dysfunction ( $P<0.005 v s$ other three groups).

In order to test whether the prognostic significance of right ventricular dysfunction for complex ventricular ectopic activity and sudden cardiac

Table 6 Right ventricular ejection fraction in relation to left ventricular ejection fraction $>0.40 \mathrm{vs} . \leqslant 0.40$ in subgroups of patients with complex ventricular arrhythmias and/or sudden cardiac death

\begin{tabular}{|c|c|c|c|c|c|c|c|c|c|c|c|c|}
\hline & \multicolumn{4}{|c|}{$\begin{array}{c}\text { LVEF }>0.40 \\
(N=99)\end{array}$} & \multicolumn{4}{|c|}{$\begin{array}{c}\text { LVEF } \leqslant 0 \cdot 40 \\
(N=28)\end{array}$} & \multicolumn{4}{|c|}{$\begin{array}{c}\text { Total } \\
(N=127)\end{array}$} \\
\hline & $\overline{\mathbf{x}}$ & \pm ISD & $N$ & $P$ & $\overline{\mathbf{x}}$ & \pm ISD & $N$ & $P$ & $\bar{x}$ & \pm ISD & $N$ & $P$ \\
\hline \multicolumn{13}{|c|}{ Lown IV } \\
\hline yes & 0.31 & 0.09 & 13 & $<0.02$ & $0 \cdot 30$ & $0 \cdot 10$ & 13 & $<0.05$ & $0 \cdot 31$ & $0 \cdot 10$ & 26 & $<0.002$ \\
\hline no & 0.38 & $0 \cdot 10$ & 86 & & 0.37 & 0.05 & 15 & & 0.38 & 0.09 & 101 & \\
\hline \multicolumn{13}{|c|}{ Sudden death } \\
\hline yes & 0.23 & 0.04 & 2 & NS & 0.28 & 0.16 & 5 & NS & 0.27 & 0.14 & 7 & NS \\
\hline no & 0.37 & $0 \cdot 10$ & 97 & 100 & 0.35 & 0.06 & 23 & 100 & $0 \cdot 37$ & 0.09 & 120 & 100 \\
\hline \multicolumn{13}{|c|}{$\begin{array}{l}\text { Lown IV andlor } \\
\text { sudden death }\end{array}$} \\
\hline yes & 0.30 & 0.09 & 15 & $<0.04$ & 0.31 & $0 \cdot 10$ & 14 & $<0.06$ & $0 \cdot 30$ & 0.09 & 29 & $<0.0003$ \\
\hline no & 0.38 & $0 \cdot 10$ & 73 & & 0.37 & 0.05 & 14 & & 0.38 & 0.09 & 98 & \\
\hline
\end{tabular}

Lown IV - patients with complex ventricular arrhythmias Lown IV, LVEF-left ventricular ejection fraction, $N$ - number of patients, NS - not significant, $P$-level of significance, RVEF - right ventricular ejection fraction, $\mathrm{SD}-$ standard deviation, $\overline{\mathrm{x}}-$ mean value. 
death was independent of the function of the left ventricle, analyses were carried out separately for patients with a left ventricular EF $>0.40 v s . \leqslant 0.40$ (Table 6). Due to the small number of patients dying during follow-up, there were no significant differences in the subgroup 'sudden death', although values of right ventricular EF were clearly depressed. Thus, complex ventricular arrhythmias and/or sudden death were related to right ventricular dysfunction, independent of left ventricular function.

\section{Discussion}

In this study, one specific explanation for the incomplete association in large clinical trials between complex ventricular arrhythmias and depressed left ventricular function after myocardial infarction was identified: right ventricular dysfunction was also a correlate and perhaps a substrate for the production of serious ventricular arrhythmias with the attendant risk of sudden cardiac death independent of and additive to left ventricular dysfunction.

Thus, complex arrhythmias were strongly related to both left and right ventricular dysfunction: the incidence was similarly increased in patients with either isolated severe depression of left or right ventricular EF and was highest in patients with biventricular dysfunction. Patients with complex ventricular arrhythmias and/or sudden cardiac death had significantly lower left and right ventricular EF than patients without such complications. Separate analyses in patients with normal vs patients with markedly depressed left ventricular function demonstrated an independent contribution of right ventricular dysfunction to the occurrence of severe arrhythmias and sudden cardiac death after myocardial infarction.

\section{RIGHT VENTRICULAR DYSFUNCTION AFTER INFERIOR} INFARCTION

Right ventricular dysfunction after inferior myocardial infarction seems to occur more frequently than previously assumed and has been reported in accordance with our findings in 30 to $70 \%$ of these patients ${ }^{[14,15,19,34,35]}$. In contrast, right ventricular scarring at autopsy has been found only in up to $43 \%$ of cases ${ }^{[36,37]}$. Several factors may account for this difference: right ventricular dysfunction may not only occur in the presence of scarring of the right ventricular free wall but may be due to abnormal septal contraction ${ }^{[38,39]}$, although we could not demonstrate such a mechanism independent of global left ventricular function. In other patients, right ventricular dysfunction may be caused by severe left ventricular dysfunction ${ }^{[40,41]}$ as shown in the present study by the association of reduced right ventricular EF in the presence of markedly depressed left ventricular function.

In addition, there is some evidence that right ventricular function may recover to a greater extent than left ventricular function after myocardial infarction ${ }^{[42,43]}$, although Marmor et al. found that this was not the case in patients with inferior infarction, right ventricular EF remaining almost unchanged over the first 10 days in these patients ${ }^{[44]}$. Therefore, we measured right ventricular EF at hospital discharge since this seems to be an appropriate point in time for risk assessment after myocardial infarction. In the present investigation there was no clinical evidence for acute increases in right ventricular afterload at the time of measurement of right ventricular EF, but a significant relation between a severely depressed right ventricular EF and a positive hepato-jugular reflux was noted.

INFERIOR INFARCTION WITH ANTERIOR ST-DEPRESSION

In patients with inferior myocardial infarction, left ventricular EF seems to be reduced to a greater extent when additional anterolateral STdepression is present as reported by Shah et al. ${ }^{[5]}$. This finding may be due to extensive inferoposterolateral infarction or additional anterior ischemia and seems to describe a subset of high risk patients with markedly depressed left and right ventricular EF. This is supported by the present study, since all 11 patients with inferior infarction and marked biventricular dysfunction and all observed deaths after inferior infarction had extensive infarction with additional anterior STsegment depression. This indicates that the subgroup of patients with inferior infarction and anterior ST-depression seems to represent a high risk population with a relatively poor prognosis.

ASSOCIATION OF VENTRICULAR ARRHYTHMIAS AND BIVENTRICULAR DYSFUNCTION

The association of left ventricular dysfunction with ventricular arrhythmias has been described after myocardial infarction ${ }^{\{7,11,13\}}$ as well as in cardiomyopathies $^{[45]}$. It is well known that right ventricular dysfunction may also be associated with ventricular arrhythmias e.g. in patients with 
pulmonary embolism ${ }^{[23]}$ or chronic obstructive pulmonary disease ${ }^{[24]}$. The present investigation showed that such a relation also exists in patients with a recent myocardial infarction independent of left ventricular function. The significance of severe right ventricular dysfunction for the occurrence of complex ventricular ectopic activity was somewhat lower than that of an impairment of the left ventricle. In addition, a depressed right ventricular EF seemed to have also a predictive value for increased mortality as has recently been described in patients with congestive heart failure associated with coronary artery disease ${ }^{[46]}$.

\section{INFLUENCE OF DRUGS/LIMITATION OF THE STUDY}

In the present investigation of a series of consecutive patients surviving a first myocardial infarction studied at hospital discharge, the incidence of ventricular ectopic activity of Lown's grades III and IV was somewhat lower than previously reported even if patients with unstable angina were excluded ${ }^{[32,33]}$. This may be due to the fact that an unselected group of patients in a community hospital without previous myocardial infarction was studied. All antiarrhythmic drugs had been stopped for at least 24 hours before the 24-hour ECG ambulatory recording. For the purpose of this prospective observational follow-up study, however, it was felt ethically not justifiable to withhold all antiarrhythmic medication and all therapy aimed at secondary prevention after myocardial infarction. Therefore, the influence of drugs on left and right ventricular function, arrhythmias and ischaemia could not be controlled further and may have influenced findings during follow-up. Due to the small number of cardiac deaths observed during the study period, it was judged statistically not feasable to apply a multiple regression type analysis for this population sample. Instead, the prognostic independence of right ventricular function was estimated separately for patients with normal or near normal $v s$. markedly depressed left ventricular EF using a cut off point of 0.40 in accordance with earlier studies on prognosis after myocardial infarction, such as the report of the Multicenter Postinfarction Research Group ${ }^{[6]}$.

\section{Conclusions}

This study demonstrates that right ventricular EF is frequently depressed in patients with recent Q-wave inferior infarction, similarly to the finding that left ventricular EF is frequently depressed in patients with recent anterior Q-wave infarction. A high risk subgroup of patients with inferior infarction and anterior ST-depression was identified with frequently depressed biventricular function and impaired prognosis. The incidence of severe ventricular arrhythmias was increased in patients with isolated right or left ventricular dysfunction compared to patients with normal function and highest in patients with severely depressed $b i$ ventricular function. Patients with complex ventricular arrhythmia and/or sudden cardiac death had significantly reduced left and right ventricular EF. Detailed analysis showed that presence of complex ventricular ectopic activity and/or sudden cardiac death after myocardial infarction was related not only to left but also separately to right ventricular dysfunction. This implies a significant contribution of right ventricular dysfunction to the occurrence of severe ventricular arrhythmias and/or sudden cardiac death after myocardial infarction independent of and additive to left ventricular dysfunction.

We are indebted to L. Glaus, PhD, Medical Department, Medical Data Analysis, Ciba-Geigy AG, Basel, Switzerland for performing all sophisticated statistical analyses. We thank L. Uebersax and R. Sieber for their help in performing the study. We appreciate the expert technical support of our cardiology and nuclear medicine staffs. We thank C. Faes for her secretarial assistance.

\section{References}

[1] Weber KT, Ratshin RA, Janicki JS, Rackley CE, Russell RP. Left ventricular dysfunction following acute myocardial infarction. Am J Med 1973; 54: 697-705.

[2] Moss AJ, DeCamilla J, Davis $\mathbf{H}$, Bayer L. The early post-hospital phase of myocardial infarction: prognostic stratification. Circulation 1976; 54: 58-64.

[3] Schelbert HR, Henning H, Ashburn WL, Verba JW Karliner JS, O'Rourke RA. Serial measurements of left ventricular ejection fraction by radionuclide angiography early and late after myocardial infarction. Am J Cardiol 1976; 38: 407-15.

[4] Taylor GJ, Humphries JO, Mellits ED, Pitt B, Schulze RA, Griffith LSC, Achuff SC. Predictors of clinical course, coronary anatomy and left ventricular function after recovery from acute myocardial infarction. Circulation 1980; 62: 960-70.

[5] Shah PK, Pichler M, Berman DS, Singh BN, Swan HJC. Left ventricular ejection fraction determined by radionuclide ventriculography in early stages of first transmural myocardial infarction. Relation to short term prognosis. Am J Cardiol 1980; 45: 542-6.

[6] The Multicenter Postinfarction Research Group. Risk stratification and survival after myocardial infarction. N Engl J Med 1983; 309: 331-6. 
[7] Schulze RA, Strauss HW, Pitt B. Sudden death in the year following myocardial infarction: relation to ventricular premature contractions in the late hospital phase and left ventricular ejection fraction. Am J Med 1977; 62: 192-9.

[8] Kotler MN, Tabatznik B, Mower MM, Tominaga S. Prognostic significance of ventricular ectopic beats with respect to sudden death in the late postinfarction period. Circulation 1973; 47: 959-64.

[9] Vismara LA, Amsterdam EA, Mason DT. Relation of ventricular arrhythmias in the late hospital phase of acute myocardial infarction to sudden death after hospital discharge. Am J Med 1975; 59: 6-12

[10] Ruberman W, Weinblatt E, Goldberg JD, Frank DW, Chaudhari BS, Shapiro S. Ventricular premature complexes and sudden death after myocardial infarction. Circulation 1981; 64: 297-305.

[11] Bigger JT, Weld FM, Rotzinsky LM. Prevalence characteristics and significance of ventricular tachycardia ( 3 or more complexes) detected with ambulatory electrocardiographic recording in the late hospital phase of acute myocardial infarction. Am J Cardiol 1981; 48: 815-30.

[12] Graboys TB, Lown B, Podrid PJ, DeSilva R. Longterm survival of patients with malignant ventricular arrhythmia treated with antiarrhythmic drugs. Am J Cardiol 1982; 50: 437-43.

[13] Humphries JO. Survival after myocardial infarction: prognosis and management. Med Concepts Cardiovasc Dis 1977; 46: 51-9.

[14] Rigo P, Murray M, Taylor DR et al. Right ventricular dysfunction detected by gated scintigraphy in patients with acute inferior myocardial infarction. Circulation 1975; 52: 268-74.

[15] Wackers FJ, Lie KI, Sohok EB, Res J, Van der Schoot JB, Durrer D. Prevalence of right ventricular involvement in inferio wall infarction assessed with myocardial imaging with thallium-201 and technetium-99m pyrophosphate. Am J Cardiol 1978; 42: 358-62.

[16] Tobinick E, Schelbert HR, Henning $\mathrm{H}$ et al. Right ventricular ejection fraction in patients with anterior and inferior myocardial infarction assessed by radionuclide angiography. Circulation 1978; 57: 1078-84.

- [17] Lorell B, Leinbach RC, Pohost GM et al. Right ventricular infarction, clinical diagnosis and differentiation from cardiac tamponade and pericardial constriction. Am J Cardiol 1979; 43: 465-71.

[18] Hirsowitz GS, Lakier JB, Marks DS, Lee TG, Goldberg D, Goldstein S. Comparison of radionuclide and enzymatic estimate of infarct size in patients with acute myocardial infarction. J Am Coll Cardiol 1983; 1 (6): 1405-12.

[19] Solèr $M$, Pfisterer $M$, Emmenegger $H$, Hiestand $B$, Burkart F. Häufigkeit und Ausmass von rechtsventrikulären Funktionsstörungen nach erstem Myokardinfarkt. Schweiz Med Wochenschr 1984; 114-16:44-9.

[20] Johnson LL, McCarthy DM, Sciarca RR, Cannon PJ. Right ventricular ejection fraction during exercise in patients with coronary artery disease. Circulation 1979; 60: 1284-91.

[21] Slutsky R, Hooper W, Gerber K et al. Assessment of right ventricular function at rest and during exercise in patients with coronary artery disease: $A$ new approach using equilibrium radionuclide angiography. Am J Cardiol 1980; 45: 63-71.
[22] Pfisterer M. Nuklearmedizinische Herzdiagnostik. Kliniktaschenbuch. Berlin: Springer-Verlag, 1982: 49-50.

[23] The urokinase-pulmonary embolism trial. A national cooperative study. Circulation 1973; 47(II): I-108.

[24] Bonsignore G, Donzelli M, Enia F et al. Cardiac arrhythmias in chronic cor pulmonale. In: Daum S, ed. Cor pulmonale chronicum. Munich: European Society of Cardiology, 1977: 509-16.

[25] World Health Organisation. Regional Office for Europe: Report of the Fifth Working Group. Copenhagen, 1971: 27-32.

[26] Lown B, Wolf M. Approaches to sudden death from coronary heart disease. Circulation 1971; 44: 130-42.

[27] Pfisterer ME, Ricci DR, Schuler G et al. Validity of left ventricular ejection fractions measured at rest and peak exercise by equilibrium radionuclide angiography using short acquisition times. J Nucl Med 1979; 20: 484-90.

[28] Pfisterer ME, Battler A, Swanson SS, Slutsky R, Froelicher V, Ashburn WL. Reproducibility of ejectionfraction determination by equilibrium radionuclide angiography in response to supine bicycle exercise. J Nucl Med 1979; 20: 491-5.

[29] Zaret BL, Battler A, Berger HJ et al. Report of the Joint International Society and Federation of Cardiology/ World Health Organization on Nuclear Cardiology. Circulation 1984; 70: 768A-81A.

[30] Pfisterer $M$, Emmenegger $H$. Non-invasive quantification of exercise-induced changes in regional left ventricular function in normals and patients with onevessel coronary artery disease using radionuclide ventriculography. Eur Heart J 1982; 3: 203-11.

[31] Pfisterer M, Glaus L, Burkart F. Comparative effects of nitroglycerine, nifedipine and metoprolol on regional left ventricular function in patients with single vessel coronary disease. Circulation 1983; 67: 291-301.

[32] Federman J, Whitford JA, Anderson ST, Pitt B. Incidence of ventricular arrhythmias in first year after myocardial infarction. Br Heart J 1978; 40: 1243-50.

[33] Kleiger RE, Miller JP, Samer Thanavaro AB, Province MA, Martin TF, Oliver GC. Relationship between clinical features of acute myocardial infarction and ventricular runs 2 weeks to 1 year after infarction. Circulation 1981; 63: 64-70.

[34] Marmor A, Geltman EM, Biello DR, Sobel BE, Siegel BA, Roberts R. Functional response of the right ventricle to myocardial infarction: dependence on the site of left ventricular infarction. Circulation 1981; 64: 1005-11.

[35] Sharpe ND, Botvinick EH, Shames DM et al. The noninvasive diagnosis of right ventricular infarction. Circulation 1978; 57: 483-90.

[36] Wortmann WB, Hellerstein HK. The incidence of heart disease in 2000 consecutive autopsies. Ann Intern Med 1948; $28: 41-65$.

[37] Erhard LR. Clinical and pathological observations in different types of acute myocardial infarction. Acta med Scand 1974; Suppl 540: 7-21.

[38] Armour JA, Lippincott DB, Randall WC. Functional anatomy of the interventricular septum. Cardiology 1973; 58: 65-72.

[39] Ferlinz J. Right ventricular function in adult cardiovascular disease. Progr Cardiovasc Dis 1982; 25: 225-67.

[40] Isner JM, Roberts WC. Right ventricular infarction 
complicating left ventricular infarction secondary to coronary heart disease. Am J Cardiol 1978; 42: 885-94.

[41] Manno BV, Iskandrian AS, Hakki A. Right ventricular function: methodologic and clinical considerations in noninvasive scintigraphic assessment. J Am Coll Cardiol 1984; 3: 1072-81.

[42] Reduto LA, Berger HJ, Cohen LS, Gottschalk A, Zaret $B L$. Sequential assessment of left and right ventricular performance after acute transmural myocardial infarction. Ann Intern Med 1978; 89: 441-7.

[43] Nemevoroski M, Shah PK, Pichler M, Berman DS, Shellock F, Swan HJC. Radionuclide assessment of sequential changes in left and right ventricular function following first acute transmural myocardial infarction. Am Heart J 1982; 104: 709-17.
[44] Marmor A, Geltman EM, Biello DR, Sobel BE, Siegel BA, Roberts R. Functional response of the right ventricle to myocardial infarction: dependence on the site of left ventricular infarction. Circulation 1981; 64: 1005-11.

[45] Segal JP, Harvy WP, Stapleton JF. Clinical features and natural history of cardiomyopathy. In: Fowler NO, ed. Myocardial diseases. New York: Grune and Stratton, 1973: 37

[46] Polak JF, Holman L, Wynne J, Colucci WS. Right ventricular ejection fraction: an indicator of increased mortality in patients with congestive heart failure associated with coronary artery disease. J Am Coll Cardiol 1983; 2: 217-24. 